\title{
Preclinical electrogastrography in experimental pigs
}

\author{
Jaroslav KVĚTINA 1, Jithinraj Edakkanambeth VARAYIL 2, Shahzad Marghoob ALI2, Martin KUNEŠ 1 , \\ Jan BUREŠ 2,3, Ilja TACHECí 2,3, Stanislav REJCHRT 2,3, Marcela KOPÁČOVÁ 2,3 \\ 1 Institute of Experimental Biopharmaceutics, Joint Research Centre of Czech Academy of Sciences and PRO.MED.CS Praha as, Hradec Králové, Czech Republic \\ 2 University Department of Gastroenterology, Charles University in Praha, Faculty of Medicine at Hradec Králové, Hradec Králové, Czech Republic \\ $32^{\text {nd }}$ Department of Internal Medicine, Charles University in Praha, Faculty of Medicine, University Teaching Hospital, Hradec Králové, Czech Republic
}

ITX030210R01 • Received:02 May 2010 • Revised:20 May 2010 • Accepted: 3 June 2010

\section{ABSTRACT}

Surface electrogastrography (EGG) is a non-invasive means of recording gastric myoelectric activity or slow waves from cutaneous leads placed over the stomach. This paper provides a comprehensive review of preclinical EGG. Our group recently set up and worked out the methods for EGG in experimental pigs. We gained our initial experience in the use of EGG in assessment of porcine gastric myoelectric activity after volume challenge and after intragastric administration of itopride and erythromycin. The mean dominant frequency in pigs is comparable with that found in humans. EGG in experimental pigs is feasible. Experimental EGG is an important basis for further preclinical projects in pharmacology and toxicology.

KEY WORDS: electrogastrography; preclinical studies; experimental pig

This paper is dedicated to the memory of Prof. Helena Rašková, MD., DSc.

\section{Introduction}

Surface electrogastrography (EGG) is a non-invasive means of recording gastric myoelectrical activity or slow waves from cutaneous leads placed over the stomach. Neuromuscular activities of the stomach generate electrical phenomena termed "gastric slow waves". The gastric myoelectrical activity is made up of two types of electrical signals termed slow waves or electrical control activity and superimposed spikes also called electrical response activity. The gastric pacemaker is located at the greater curvature of stomach adjacent to the junction between the fundus and the body (Chen \& McCallum, 1994; Parkman et al., 2003; Chang, 2005).

Correspondence address:

Prof. Jaroslav Květina, DSc., Dr.h.c.

Institute of Experimental Biopharmaceutics,

Joint Research Centre of Czech Academy of Sciences and

PRO.MED.CS Praha a.S.

Heyrovského 1207, CZ-50002 Hradec Králové, Czech Republic

E-MAlL: kvetina@uebf.cas.cz

\section{Assessment of motor function of the stomach}

Normal gastrointestinal motor function is a complex series of events that requires coordination of the sympathetic and parasympathetic nervous systems, neurons within the stomach and intestine, as well as the smooth muscle cells of the gut. Several tools are available to evaluate motor function and related disorders, like EGG, gastric emptying tests (gastric scintigraphy, breath tests using ${ }^{13} \mathrm{C}$-octanoic acid, ${ }^{13} \mathrm{C}$-acetate or spirulina, a plant based protein), gastroduodenal manometry, electronic barostat and planimetry of the gastric antrum by abdominal ultrasonography or magnetic resonance. Simultaneous measurement of intra-luminal $\mathrm{pH}$ and pressure by a special capsule is a new method of investigation (Camileri et al., 1998; 2010). The capsule, when swallowed, can simultaneously measure phasic pressure amplitudes and $\mathrm{pH}$ as it traverses different segments of the gastrointestinal tract. The characteristic change in $\mathrm{pH}$ between the stomach and the small intestine provides an indication of the gastric emptying time for a non-digestible solid $>1 \mathrm{~cm}$ long (Camilleri, 2010).

Fasted and postprandial recording running spectrum percent activity and changes in the aplitude (power 
analysis) are the major measures for the evaluation of EGG. According to the American Motility Society (Parkman et al., 2003), normal EGG frequency (2.0-4.0 cycles per minute) should comprise $\geq 70 \%$ of recording time in humans. The possible relationship between EGG and gastric emptying also remains controversial (Mintchev et al., 1993; Bortolotti, 1998; Sanmiguel et al., 1998; Sha et al., 2009). The major parameters of EGG and gastric emptying measures (e.g. half-life of elimination in ${ }^{13} \mathrm{C}$-octanoic acid breath test) mutually correlate in healthy humans (Bureš et al., 2007). There could probably be a difference between healthy status and disease (i.e. diabetes mellitus, systemic sclerosis, functional dyspepsia, eating disorders, gastrectomy etc.) (Chen \& McCallum, 1994; Diamanti et al., 2003; Bureš et al., 2007; 2008; Camileri et al., 2010).

In humans, pathological changes at EGG, i.e. alterations in frequency (bradygastria, tachygastria, or mixed, dysrhytmias) and reduction in the amplitude of the postprandial electrical signal are seen in patients with idiopathic and diabetic gastroparesis, functional dyspepsia, anorexia nervosa, nausea of pregnancy, vector/ motor sickness, Helicobacter pylori infection, status after gastric surgery. Dysrhythmias have also been described in patients with functional dyspepsia, with or without evidence of gastric stasis (Chen \& McCallum, 1994; 2006; Bureš et al., 1998; 2008; Sanmiguel et al., 1998; Ogawa et al., 2004). In healthy people, dominant frequency varies during the day (maximum frequency at midday and minimum frequency during the night) (Lindberg et al., 1996). Age, sex (including menstrual cycle in women) and body-mass index might influence EGG in humans (Real Martínez et al., 2001; Tojl et al., 2007). However, even more physiological and/or social events can influence EGG in humans, like meals and volume challenge, ethanol intake, listening to enjoyable music etc. (Levanon et al., 1998; Lin et al., 2007; Kobak \& Bor, 2007).

\section{Importance of preclinical studies}

In humans, several drugs were tested to influence myoelectrical activity of the stomach, like prokinetics (cisapride, tegaserod, domperidon), muscarinic M3 receptor agonists (cevimeline), hyoscine butylbromide, fentanyl and others (Chiba et al., 2007; Walldén et al., 2008; Americo et al., 2009). Interestingly, probiotics and prebiotics might influence EGG in humans too. Probiotic Lactobacillus reuteri stimulated gastric emptying and improved maturation of the EGG activity mimicking the effect of breast milk in preterm infants (Indrio et al., 2009).

The precise role of EGG in the clinical evaluation of patients or monitoring of therapeutic response to medications, and how this test adds to the information obtained from a gastric emptying test, remain the subject of ongoing research.

The pig, as a representative of the omnivore, is relatively close to man in a number of metabolic and physiological indicators (Květina et al., 1999; Nobilis et al., 2003; Anzenbacherová et al., 2003). It is not uncommon that prediction focusing on the transfer of knowledge towards human drug therapy is based on precisely this experimental species (Květina et al., 2009). Regarding body mass index, in the case of use of small adult pigs in a body weight range of $30-40 \mathrm{~kg}$, the proportions of passive (fat) and active (muscle) masses are comparable to an adult man. Conversion of doses of studied xenobiotics and even manner and form of their administration becomes relatively comparable (Květina et al., 2008b). Contrary to clinical observations, experimental design allows for standardisation of the experiment set and identification and definition of the test conditions.

\section{Electrogastrography in experimental pigs}

The small adult pig can be used in various preclinical experiments as a representative of the omnivore due to its relatively very similar gastrointestinal functions in comparison to man (Kararli, 1995). However, there are some distinct differences in the anatomy and physiology of the stomach between humans and pigs (Bureš et al., 2009; Kopáčová et al., 2010; Květina et al., 2008a). The porcine stomach is pouch-shaped and the gastric cardia is close to the pylorus. A special transverse pyloric fold (torus pyloricus) serves as a "gate-keeper" (Kopáčová et al., 2010). Gastric emptying of pigs is much slower, put through small separated amounts. There are significant remnants of food in the porcine stomach even after 36-48 hours of fasting (Kopáčová et al., 2010; Tachecí et al., 2009).

To the best of our knowledge, there are no previous reports on EGG in pigs in the available literature. Our group recently set up and worked out the methods for EGG in experimental pigs (Varayil et al., 2009). All EGG recordings were carried out under general anaesthesia (introduction: intramuscular administration of ketamin and azaperone, repeated doses of thiopental when appropriate).

In our setting, all animals were lying in a right lateral position during the EGG recording. The epigastric area was shaved before application of electrodes to decrease impedance in signal conduction through the skin. Electrode placement always began with placing the first electrode roughly within $5 \mathrm{~cm}$ of the xyphoid process in the centre and then subsequently placing the other 2 roughly at a distance of $15 \mathrm{~cm}$ from the central electrode in left and right hypochondrium respectively (Figure 1). After connecting the device the recording was started and the animals were closely monitored for any flinging movement. A single EGG recording always lasted 30 minutes. All possible artefacts (especially motion ones) must be removed before the final evaluation. We used a running spectral analysis (based on Fourier transform) for the evaluation of the experimental EGG. Results are expressed as running spectrum percent activity. All low, medium and high frequencies of gastric slow waves were found in particular animals (Figures 2-7). The normal dominant frequency that we found in pigs in this project 
( $3.3 \pm 0.5$ cycles per minute) is fully comparable with those in adult humans (Varayil et al., 2009). Thus our original assumption was proven - the young adult pig is a suitable model for experimental EGG.

\section{Volume challenge}

The water load test is a standardised test to induce gastric distension and to evoke gastric motility responses without the complex hormonal response of a caloric test meal. EGG with water load test has been validated as being reliable and reproducible in humans (Koch et al., 2000; Chen et al., 2006).

In our recent EGG study in experimental pigs, we decided on volume challenge of $360 \mathrm{~mL}$ water that is comparable with $500 \mathrm{~mL}$ usually used in adult humans. The mean dominant frequency after volume challenge was significantly higher compared with the basic measurement (Varayil et al., 2009). Several studies performed previously in humans have shown that volume overload after drinking water generally affects both dominant frequency (to tachygastria) and dominant power (characterised by an increase in amplitude) which has been attributed to factors such as 1) gastric distension 2) gastric displacement 3) slow wave changes and/or 4) neurohumoral mechanisms (Chen et al., 2006; Friesen et al., 2007; Jones et al., 2003; Lin et al., 2000).

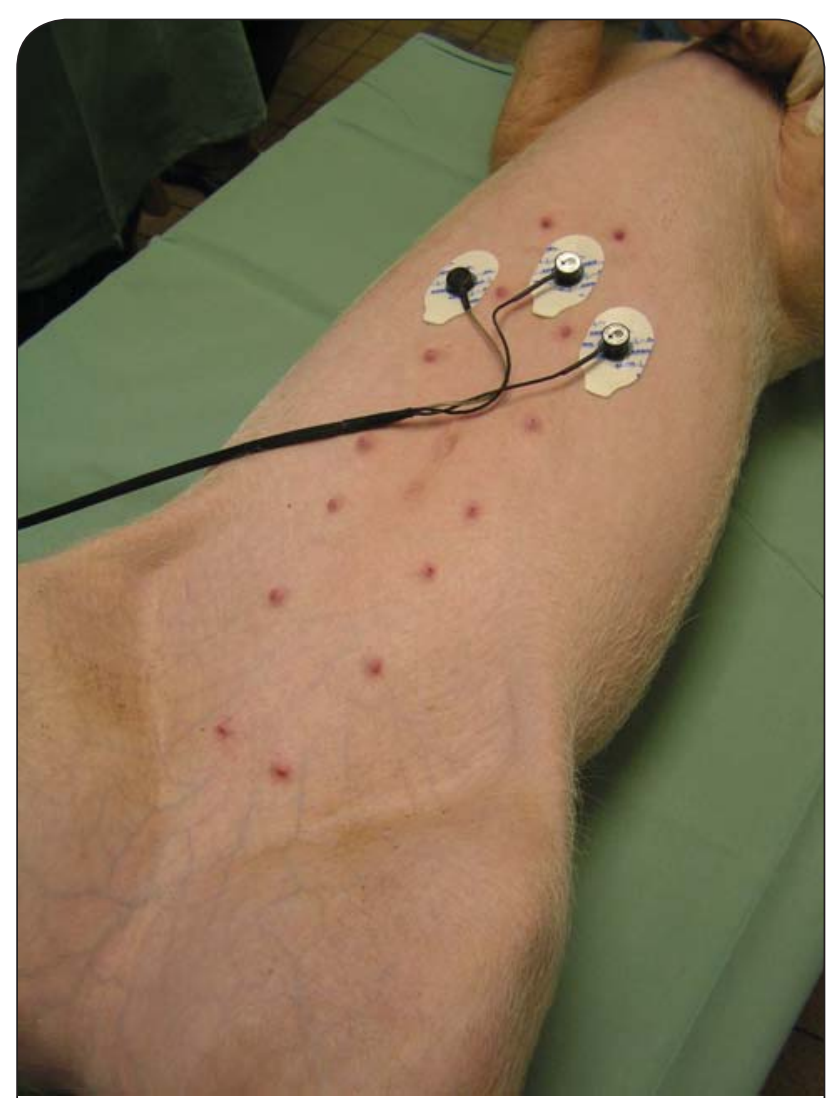

Figure 1. Electrogastrography in experimental pigs. General arrangement of the electrodes placement for EGG recording.

\section{Itopride}

Itopride is a dopamine D2 antagonist with acetylcholinesterase inhibitory activity that has prokinetic effects and probably effects on gastric accommodation and hypersensitivity (Longstreth, 2010).

We used itopride as a model prokinetic drug in experimental pigs. EGG recording was carried out immediately after intragastric administration of $100 \mathrm{mg}$ itopride (i.e. $\sim 3 \mathrm{mg} / \mathrm{kg}$; corresponding to the maximum single dose for man). There was no obvious change in dominant frequency during subsequent EGG recording (Varayil et al., 2009). However, it is possible that the dose was not big enough and/or there was not the required time to make it possible for itopride to exert its prokinetic effect. Itopride has linear kinetics. In humans, maximum plasmatic concentration ( $t$-max) of itopride is reached at about 45 minutes after oral administration (half-time of elimination is 6 hours). Gastric emptying and start of intestinal absorption of itopride might be delayed under general anaesthesia (Schurizek, 1991; Umenai et al., 2009). Iwanaga et al. (1996) studied the gastroprokinetic effect of itopride in conscious dogs. At a dose of $3 \mathrm{mg} / \mathrm{kg}$, itopride did not affect gastrointestinal motility. With itopride 10 $\mathrm{mg} / \mathrm{kg}$ the contractile force of the gastric antrum was increased (doubled) within 5 minutes after intra-duodenal administration of itopride (Iwanaga et al., 1996).

\section{Erythromycin}

Macrolides are a group of closely related antibiotics characterised by a 14-, 15- or 16-membered lactone ring. Macrolides have been found to have pharmacodynamic properties beyond their antimicrobial mode of action, like anti-inflammatory, immunomodulatory and gastrointestinal prokinetic effects (Hawkyard \& Koerner, 2007). Erythromycin is the most potent prokinetic drug available nowadays. Erythromycin has been shown to initiate gastric interdigestive migrating motor complexes, which are the motor events responsible for gastric emptying of indigestible solids. Erythromycin induces high amplitude gastric propulsive contractions that literally dump solid residue, including non-digestible materials, out of the stomach (Prather et al., 1993; Keshavarzian, 1993; Curry et al., 2001). Erythromycin also stimulates fundic contractility, or at least inhibits the accommodation response of the proximal stomach after food ingestion (Bruley des Varannes et al., 1995; Fraser \& Mittal, 1994; Curry et al., 2001; Camilleri, 2010). Erythromycin seems to have a different mechanism of action in the stomach compared to the duodenum (Mathis \& Malbert, 1995).

Erythromycin is used especially in the treatment of diabetic gastroparesis in humans (Camilleri, 2010). A systematic review identified 35 clinical trials involving erythromycin for gastroparesis of which five fulfilled inclusion criteria for the review (Maganti, 2003). All studies were small ( $\leq 13$ subjects), of short duration ( $\leq 4$ weeks) and had methodological weaknesses. Nevertheless, improvement 


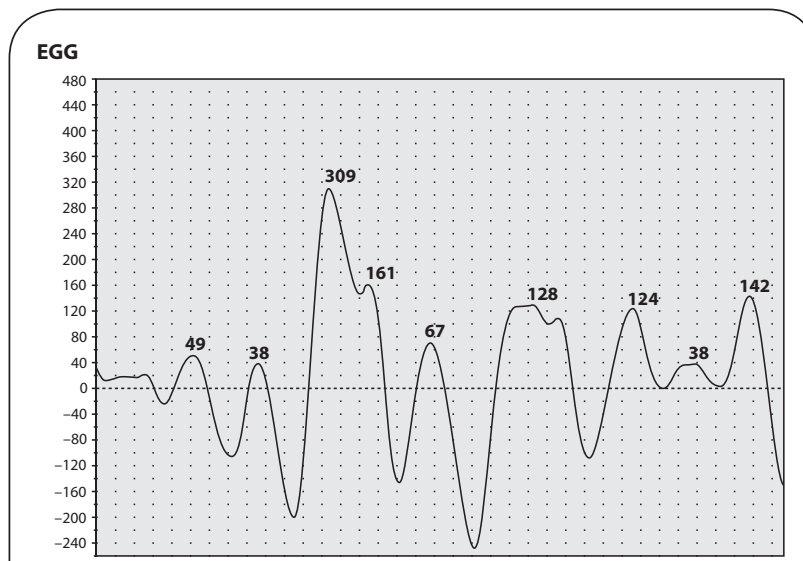

Figure 2. EGG rhythm of three cycles per minute at online recording.

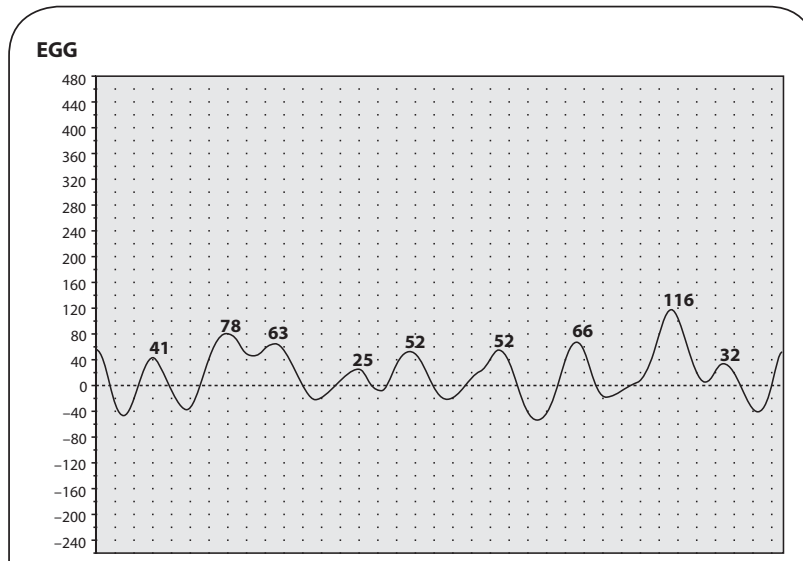

Figure 4. Pattern of bradygastria at online EGG recording

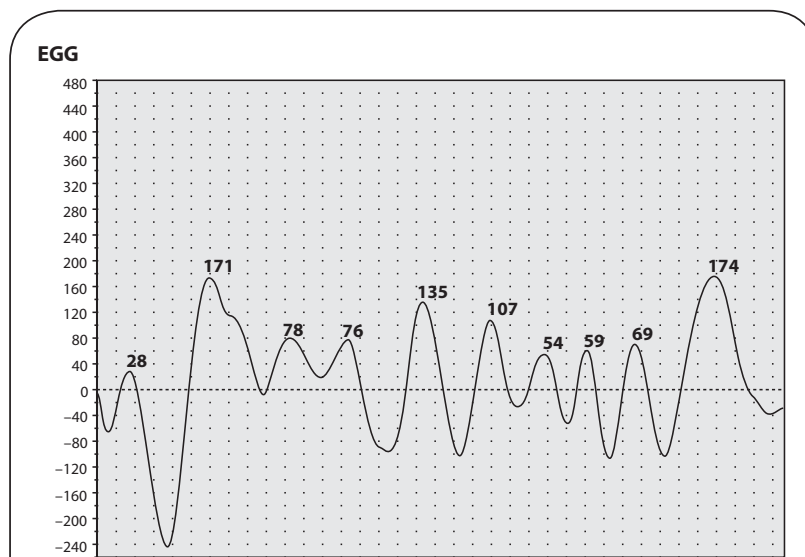

Figure 6. Pattern of tachygastria at online EGG recording.

was reported in 26 of 60 patients (43\%) (Maganti et al., 2003). Van der Voort et al. (2003) investigated functional dyspepsia, irritable bowel syndrome and healthy controls. Disturbed gastric emptying correlated with a lack of postprandial increase in the EGG amplitude. Prokinetic

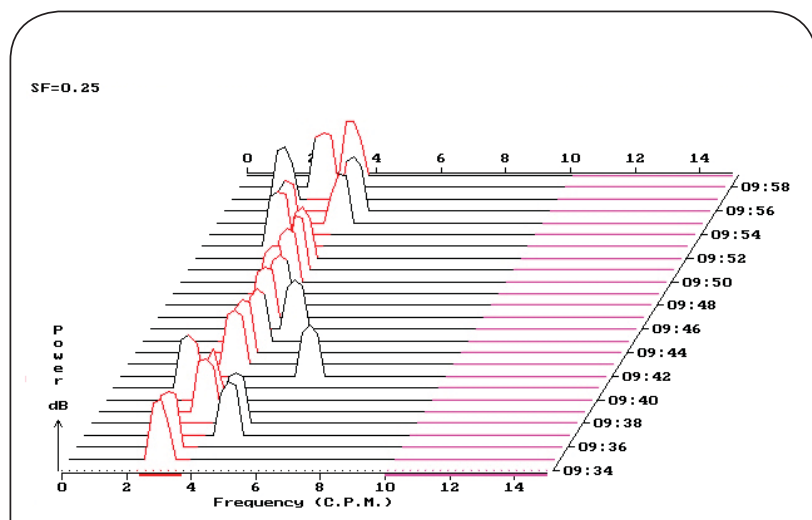

Figure 3. Protocol of EGG recording with prevailing rhythm of three cycles per minute ( $60 \%$ running spectrum percent activity).

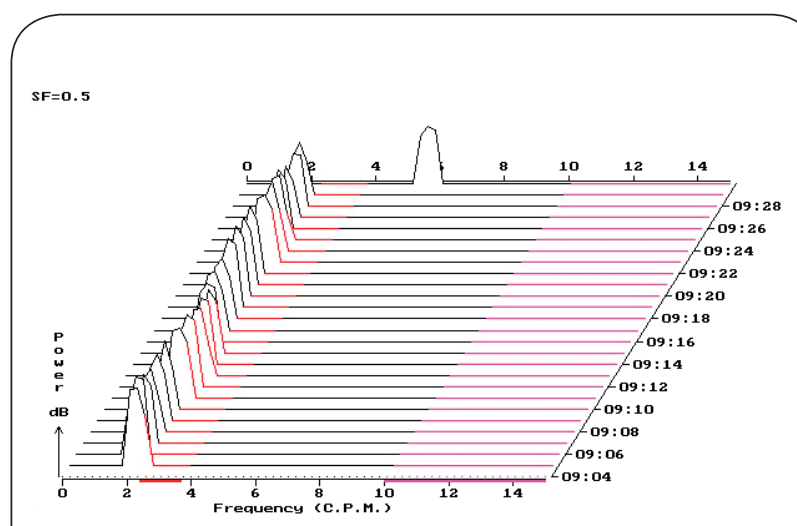

Figure 5. Protocol of EGG recording with prevailing bradygastria (96\% running spectrum percent activity).

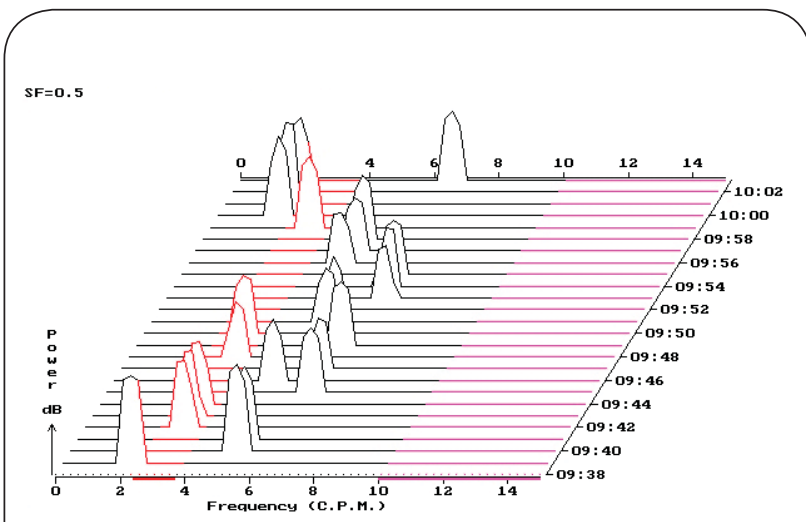

Figure 7. Protocol of EGG recording with prevailing tachygastria (60\% running spectrum percent activity).

erythromycin improved both gastric emptying and gastric electrical activity (van der Voort et al., 2003).

In our latest project, we used EGG to test the effect of erythromycin on gastric myoelectrical activity in experimental pigs. Intragastric administration of a therapeutic 
dose of erythromycin (1600 mg) substantially increased the gastric myoelectrical activity. There was a significant prokinetic effect of erythromycin (compared to baseline recording): a statistically significant increase in dominant frequency at recordings starting 90 minutes with maximum 330 minutes after erythromycin administration. In a human study in healthy volunteers, low dose i.v. erythromycin also achieved an increase in percent tachygastria (DiBaise et al., 2001).

\section{Tasks and perspectives for future}

Further improvements in methods of EGG in experimental pigs are needed. Optimal placement of leads must be searched for before each recording (different for drug testing and volume challenge). Power analysis must become an inherent part of each evaluation. It will be also useful to verify and validate if the ratio of antral motor index is beneficial in experimental pigs. This index is calculated as the number of waves the sum of amplitudes (Faure et al., 2000). And last but not least, standard protocol of EGG in experimental pigs must be completed.

Not only several drugs, but also different probiotic bacteria are to be tested by means of EGG in the near future. Experimental EGG is an optimal non-invasive method to investigate the motor effect of particular drugs.

\section{Conclusions}

EGG in experimental pigs is feasible. The mean dominant frequency in pigs is comparable with that found in humans. Experimental EGG is an important basis for further preclinical projects in pharmacology and toxicology.

\section{Acknowledgement}

The study was supported by research grant GAČR 305/08/0535, Czech Republic and by research project MZO 00179906 from the Ministry of Health of the Czech Republic.

Conflicts of interests: The authors disclose no conflicts.

\section{REFERENCES}

Américo MF, Miranda JR, Corá LA, Romeiro FG. (2009). Electrical and mechanical effects of hyoscine butylbromide on the human stomach: a non-invasive approach. Physiol Meas 30(4): 363-370.

Anzenbacherová E, Anzenbacher P, Svoboda Z, Ulrichová J, Květina J, Zoulová J, Perlík F, Martínková J. (2003). Minipig as a model for drug metabolism in man: comparison of in vitro and in vivo metabolism of propafenone. Biomed Papers 147: 155-159.

Bortolotti M. (1998). Electrogastrography: a seductive promise, only partially kept. Am J Gastroenterol 93: 1791-1794.

Bruley des Varannes S, Parys V, Ropert A, Chayvialle JA, Rozé C, Galmiche JP. (1995). Erythromycin enhances fasting and postprandial proximal gastric tone in humans. Gastroenterology 109(1): 32-39.
Bureš J, Kabelác K, Kopácová M, Vorísek V, Siroký M, Palicka V, Rejchrt S. (2008). Electrogastrography in patients with Roux-en-Y reconstruction after previous Billroth gastrectomy. Hepatogastroenterology 55(85): 1492-1496.

Bureš J, Kopácová M, Kvetina J, Osterreicher J, Sinkorová Z, Svoboda Z, Tachecí I, Filip S, Spelda S, Kunes M, Rejchrt S. (2009). Different solutions used for submucosal injection influenced early healing of gastric endoscopic mucosal resection in a preclinical study in experimental pigs. Surg Endosc 23(9): 2094-2101.

Bureš J, Kopáčová M, Voříšek V, Bukač J, Neumann D, Živný P, Palička V, Rejchrt S. (2007). Correlation of electrogastrography and gastric emptying rate estimated by ${ }^{13} \mathrm{C}$-octanoic acid breath test in healthy volunteers. Folia Gastroenterol Hepatol 5(1): 5-11.

Bureš J, Rejchrt S, Široký M, Kopáčová M, Živný P, Palička V. (1998). Electrogastrography in anorexia nervosa. Digestion 59(Suppl 3): 247.

Camilleri M, Hasler WL, Parkman HP, Quigley EM, Soffer E. (1998). Measurement of gastrointestinal motility in the Gl laboratory. Gastroenterology $\mathbf{1 1 5}$ 747-762.

Camilleri M. (2010). Etiology and diagnosis of delayed gastric emptying. Treatment of delayed gastric emptying. UpToDate on line, 18.1. Wellesley. Available from http://www.uptodate.com

Chang FY. (2005). Electrogastrography: basic knowledge, recording, processing and its clinical applications. J Gastroenterol Hepatol 20(4): 502-516.

Chen C-L, Hu C-T, Lin H-H, Yi C-H. (2006). Clinical utility of electrogastrography and the water load test in patients with upper gastrointestinal symptoms. J Smooth Muscle Res 42(5): 149-157

Chen JZ, McCallum RW (eds). (1994). Electrogastrography. Principles and Applications. NewYork: Raven Press.

Chiba T, Kudara N, Sato M, Inomata M, Orii S, Suzuki K. (2007). Effect of muscarinic M3 receptor agonist on gastric motility. J Gastroenterol Hepatol 22(11): 2039-2041.

Curry J, Lander TD, Stringer MD. (2001). Review article: erythromycin as a prokinetic agent in infants and children. Aliment Pharmacol Ther 15(5): 595-603.

Diamanti A, Bracci F, Gambarara M, Ciofetta GC, Sabbi T, Ponticelli A, Montecchi F, Marinucci S, Bianco G, Castro M. (2003). Gastric electric activity assessed by electrogastrography and gastric emptying scintigraphy in adolescents with eating disorders. J Pediatr Gastroenterol Nutr 37(1): 35-41.

DiBaise JK, Park FL, Lyden E, Brand RE, Brand RM. (2001). Effects of low doses of erythromycin on the $13 \mathrm{C}$ Spirulina platensis gastric emptying breath test and electrogram: a controlled study in healthy volunteers. Am J Gastroenterol 96(7): 2041-2050.

Faure C, Wolff VP. Navarro J. (2000). Effect of meals and intravenous erythromycin on manometric and electrogastrographic measurements of gastric motor and electrical activity. Dig Dis Sci 45(3): 525-528.

Fraser RJ, Mittal RK. (1994). Erythromycin: the mechanism of its prokinetic action in the treatment of gastroparesis. Gastroenterology 107(6): 1904-1905

Friesen CA, Lin Z, Schurman JV, Andre L, Mc Callum RW. (2007). Autonomic nervous system response to a solid meal and water loading in healthy children: its relation to gastric myoelectrical activity. Neurogastroenterol Motil 19: 376-382.

Hawkyard CV, Koerner RJ. (2007). The use of erythromycin as a gastrointestinal prokinetic agent in adult critical care: benefits versus risks. J Antimicrob Chemother 59: 347-358.

Indrio F, Riezzo G, Raimondi F, Bisceglia M, Cavallo L, Francavilla R. (2009). Effects of probiotic and prebiotic on gastrointestinal motility in newborns. Physiol Pharmacol60(Suppl 6): 27-31.

Iwanaga Y, Miyashita N, Saito T, Morikawa K, Itoh Z. (1996). Gastroprokinetic effect of a new benzamide derivate itopride and its action mechanism in conscious dogs. Jpn J Pharmacol 71: 129-137.

Jones MP, Hoffman S, Shah D, Patel K, Ebert CC. (2003). The water load test: observations from healthy controls and patients with functional dyspepsia. Am J Physio/ Gastrointest Liver Physio/ 284: G896-G904.

Kararli TT. (1995). Comparison of the gastrointestinal anatomy, physiology and biochemistry of humans and commonly used laboratory animals. Biopharm Drug Dispos 16: 351-380.

Keshavarzian A, Isaac RM. (1993). Erythromycin accelerates gastric emptying of indigestible solids and transpyloric migration of the tip of an enteral feeding tube in fasting and fed states. Am J Gastroenterol 88: 193-197.

Kobak AC, Bor S. (2007). The acute effect of oral ethanol intake on gastric myoelectrical activity in healthy volunteers. Turk J Gastroenterol 18(4): 221-224. 
Koch KL, Hong SP, Xu L. (2000). Reproducibility of gastric myoelectrical activity and the water load test in patients with dysmotility-like dyspepsia symptoms and in control subjects. J Clin Gastroentero/ 31(2): 125-129.

Kopáčová M, Tachecí I, Květina J, Bures J, Kunes M, Spelda S, Tycová V, Svoboda Z, Rejchrt S. (2010). Wireless video capsule enteroscopy in preclinical studies: Methodical design of its applicability in experimental pigs. Dig Dis Sci 55(3): 626-630.

Květina J, Bureš J, Svoboda $Z$, Kuneš $M$, Kopáčová $M$, Nobilis $M$, Špelda $S$. (2008). Experimental pig: the relationship between intestinal desintegration of tablets drug formulations scanned with microcamera and bioavailability of active component in system circulation. Physiol Res 57: 3P.

Květina J, Kunes M, Bures J, Kopacova M, Tachecí I, Spelda S, Herout V, Rejchrt S. (2008). The use of wireless capsule enteroscopy in a preclinical study: a novel diagnostic tool for indomethacin-induced gastrointestinal injury in experimental pigs. Neuroendocrinol Lett 29(5): 763-769.

Květina J, Kuneš $M$, Herout $V$, Novotný $L$, Bureš J, Kopáčová $M$, Tachecí I. (2009). The dynamics of gastrointestinal lesions induced by indomethacin: the interspecies comparison (laboratory rat, experimental pig). Toxicology Letters 164: 189S.

Květina J, Svoboda Z, Nobilis M, Pastera J, Anzenbacher P. (1999). Experimental Goettingen minipig and beagle dog as two species used in bioequivalence studies for clinical pharmacology (5-aminosalicylic acid and atenolol as model drugs). Gen Physiol Biophys 18: 80-85.

Levanon D, Zhang M, Orr WC, Chen JDZ. (1998). Effects of meal volume and composition on gastric myoelectrical activity. Am J Physio/ 274: G430-G434.

Lin HH, Chang WK, Chu HC, Huang TY, Chao YC, Hsieh TY. (2007). Effect of music on gastric myoelectrical activity in healthy humans. Int $J$ Clin Pract 61(7): 1126-1130.

Lin Z, Chen JD, Schirmer BD, McCallum RW. (2000). Postprandial response of gastric slow waves: correlation of serosal recordings with electrogastrogram. Dig Dis Sci 45: 645-651.

Lindberg G, Iwarzon M, Hammarlund B. (1996). 24-hour ambulatory electrogastrography in healthy volunteers. Scand J Gastroentero/ 31(7): 658-664.

Longstreth GF. (2010). Approach to the adult with nausea and vomiting. UpToDate on line, 18.1. Wellesley. Available from http://www.uptodate.com

Maganti K, Onyemere K, Jones MP. (2003). Oral erythromycin and symptomatic relief of gastroparesis: a systematic review. Am J Gastroenterol 98: 259-263.

Mathis C, Malbert CH. (1995). Gastric but not duodenal motor effects of oral erythromycin are dose related. Neurogastroenterol 7(1): 47-54.

Mintchev MP, Kingma YJ, Bowes KL. (1993). Accuracy of cutaneous recording of gastric electrical activity. Gastroenterology 104: 1273-1280.

Nobilis M, Kopecký J, Květina J, Svoboda Z, Pour M, Kuneš J, Holčapek M, Kolářová L. (2003). Comparative biotransformation and disposition studies of nabumetone in human and minipigs using high performormance liquid chromatography with ultraviolet and mass-spectrometric detection. $J$ Pharm Biomed Anal 32: 641-656.
Ogawa A, Mizuta I, Fukunaga T, Takeuchi N, Honaga E, Sugita Y, Mikami A, Inoue Y, Takeda M. (2004). Electrogastrography abnormality in eating disorders. Psychiatry Clin Neurosci 58(3): 300-310.

Parkman HP, Hasler WL, Barnett JL, Eaker EY, American Motility Society Clinical GI Motility Testing Task Force. (2003). Electrogastrography: a document prepared by the gastric section of the American Motility Society Clinical GI Motility Testing Task Force. Neurogastroenterol Motil 15: 89-102.

Prather CM, Camilleri M, Thomforde GM, Forstrom LA, Zinsmeister AR. (1993). Gastric axial forces in experimentally-delayed and accelerated gastric emptying. Am J Physio/ 264: G928-G934.

Real Martínez Y, Ruiz de León San Juan A, Díaz-Rubio M. (2001). Normal values and influence of anthropometric and demographic factors on ambulatory cutaneous electrogastrography in healthy volunteers. Rev Esp Enferm Dig 93: 29-38.

Sanmiguel CP, Mintchev MP, Bowes KL. (1998). Electrogastrography: a noninvasive technique to evaluate gastric electrical activity. Can J Gastroenterol 12: 423-430.

Schurizek BA. (1991). The effect of general anaesthesia on antroduodenal motility, gastric pH and gastric emptying in man. Dan Med Bull 38(4): $347-$ 365.

Sha W, Pasricha PJ, Chen JD. (2009). Correlations among electrogastrogram, gastric dysmotility, and duodenal dysmotility in patients with functional dyspepsia. J Clin Gastroenterol 43(8): 716-722.

Tachecí I, Květina J, Bureš J, Osterreicher J, Kuneš M, Pejchal J, Rejchrt S, Spelda S, Kopáčová M. (2009). Wireless capsule endoscopy in enteropathy induced by nonsteroidal anti-inflammatory drugs in pigs. Dig Dis Sci Dec. 16. PMID: 20013311 [Epub ahead of print].

Tolj N, Luetic K, Schwarz D, Bilić A, Jurcić D, Gabrić M. (2007). The impact of age, sex, body mass index and menstrual cycle phase on gastric myoelectrical activity characteristics in a healthy Croatian population. Coll Antropol 31: 955-962.

Umenai T, Arai N, Chihara E. (2009). Effect of the preliminary hydration on gastric emptying time for water in healthy volunteers. Acta Anaesthesiol Scand 53(2): 223-226.

van der Voort IR, Osmanoglou E, Seybold M, Heymann-Monnikes I, Tebbe J, Wiedenmann B, Klapp BF, Monnikes H 2003. Electrogastrography as a diagnostic tool for delayed gastric emptying in functional dyspepsia and irritable bowel syndrome. Neurogastroenterol Motil 15: 467-473.

Varayil JE, Ali SM, Tachecí I, Květina J, Kopáčová M, Kuneš M, Rejchrt S, Bureš J. (2009). Electrogastrography in experimental pigs. Methodical design and initial experience. Folia Gastroenterol Hepatol 7(3-4): 98-104. Available from www.pro-folia.org

Walldén J, Lindberg G, Sandin M, Thörn SE, Wattwil M. (2008). Effects of fentanyl on gastric myoelectrical activity: a possible association with polymorfisms of the mu-opioid receptor gene? Acta Anaesthesiol Scand 52(5): 708-715. 